Isabele Campos Costa Amaral Leandro Vargas Barreto de Carvalho Joyce Neri da Silva Pimentela Angélica Cardoso Pereira Jilica Cardoso Pereira Jucilene Aparecida Vieira Vinicio Soares de Castro Renato Marçullo Borges Sérgio Rabello Alves ${ }^{\mathrm{a}}$

Simone Mitri Nogueira

Marianne de Medeiros Tabalipa

Ubirani Barros Otero

Katia Maria Pinto Guedes de Oliveirac

Sérgio Machado Corrêa

Antônio Sérgio Almeida Fonseca ${ }^{\mathrm{a}}$

Josino Costa Moreira

Frederico Peres ${ }^{\mathrm{a}}$

Liliane Reis Teixeira ${ }^{a}$

Marco Antônio Carneiro Menezes

Rita de Cássia Oliveira da Costa Mattos ${ }^{\mathrm{a}}$

Paula de Novaes Sarcinellia

Ariane Leites Larentis ${ }^{\mathrm{a}}$

${ }^{a}$ Fundação Oswaldo Cruz (Fiocruz), Escola Nacional de Saúde Pública Sergio Arouca (ENSP), Centro de Estudos da Saúde do Trabalhador e Ecologia Humana (CESTEH). Rio de Janeiro, RJ, Brasil.

${ }^{b}$ Instituto Nacional do Câncer (INCA). Coordenação de Prevenção e Vigilância. Area de Vigilância do Câncer Relacionado ao Trabalho e ao Ambiente. Rio de Janeiro, RJ, Brasil.

' Universidade Federal Fluminense (UFF). Campus do Valonguinho. Departamento de Química. Niterói, RJ, Brasil.

dUniversidade Estadual do Rio de Janeiro (UERJ). Departamento de Química e Ambiental. Resende, RJ, Brasil.

Contato:

Isabele Campos Costa-Amara

E-mail:

costa.isabele@gmail.com

Os autores declaram não haver conflitos de interesses.

Este artigo faz parte do projeto "Caracterização de riscos relacionados à exposição ocupacional ao benzeno em postos de gasolina do município do Rio de Janeiro: estudo-piloto" desenvolvido por meio de parceria entre os autores e suas respectivas instituições.

Este estudo recebeu fomento através de cooperação interinstitucional (2010-2012) com a Coordenação Geral de Vigilância em Saúde Ambiental (CGVAM/SVS/Ministério da Saúde), do Programa Inova-ENSP (Edital 2013-2015 do Programa de Apoio à Pesquisa, Desenvolvimento e Inovação em Saúde Pública da ENSP/Fiocruz). Edital Faperj no 32/2013 - Programa Apoio às Institiçoes de Ensino e Pesquisa Se no Estado do Rio de Janeiro - 2013 (Processo E-26/111.732/2013) e do Chamamento Público $n^{\circ}$ 05/2014 - Iniciativas Educacionais Aplicadas à Vigilância em Saúde da Secretaria de Vigilância em Saúde do Ministério da Saúde (SVS/MS), por meio do CESTEH, Centro Colaborador da OPAS/ OMS para Saúde Pública e Ambiental.

Os autores informam que o trabalho não fo baseado em tese e não foi apresentado em reunião científica.

Submetido: 14/09/2015

Revisado: 08/07/2016

Aprovado: 11/07/2016

\section{Avaliação ambiental de BTEX (benzeno, tolueno, etilbenzeno, xilenos) e biomarcadores de genotoxicidade em trabalhadores de postos de combustíveis}

\author{
Environmental assessment of BTEX (benzene, toluene, \\ ethylbenzene, xylenes) and biomarkers of genotoxicity in gas \\ stations workers
}

\section{Resumo}

Introdução: trabalhadores de postos de combustíveis estão expostos às diversas substâncias químicas presentes no ambiente de trabalho, destacando-se entre elas o benzeno, devido às suas propriedades carcinogênicas. Objetivo: avaliar os danos genotóxicos relacionados à exposição ocupacional ao BTEX (benzeno, tolueno, etilbenzeno, xilenos) em trabalhadores de cinco postos de combustíveis do município do Rio de Janeiro, RJ. Metodologia: foram analisadas concentrações de BTEX no ar; atividades das enzimas catalase e glutationa $S$-transferase; e ensaio cometa em amostras de sangue total de 97 trabalhadores. Resultados: as concentrações de BTEX estavam dentro dos valores preconizados pela NR 15, incluindo Anexo 13-A. Entretanto, uma oscilação nos resultados de ensaio cometa foi observada entre os trabalhadores dos diferentes postos de combustíveis, principalmente em trabalhadores de postos com menores concentrações de benzeno. Discussão: esse resultado está de acordo com a literatura científica atual, que indica uma curva dose-resposta supralinear para o benzeno, observando-se em baixas concentrações um aumento não linear do risco de leucemia, provavelmente relacionado à maior metabolização do benzeno e à maior produção de seus metabólitos tóxicos nessas concentrações. Conclusão: os resultados deste estudo sugerem que a exposição ao BTEX, mesmo em baixas concentrações, contribui para o risco genotóxico à saúde humana. Palavras-chave: saúde ocupacional; postos de combustíveis; BTEX; ensaio cometa; estresse oxidativo.

\begin{abstract}
Introduction: gas station workers are exposed to several chemicals in their workplace, highlighting benzene, due to its carcinogenic properties. Objective: to assess the genotoxic damage related to occupational exposure to BTEX (benzene, toluene, ethylbenzene, xylenes) in workers of five gas stations in Rio de Janeiro, RJ. Methods: analysis of BTEX concentrations in the air were carried out; as well as activities of catalase and glutathione S-transferase; and comet assay in whole blood samples of 97 workers. Results: BTEX levels were within the Brazilian threshold levels recommended by the NR 15, including Annex 13-A. However, an oscillation of the comet assay results was observed among workers of different gas stations, mainly in workers from gas stations with lower concentrations of benzene. Discussion: this result is in accordance with the current international scientific literature that indicates a supralinear exposure-response curve for benzene. In lower concentrations we could observe a high non-linear risk of leukemia, probably due to a greater benzene metabolism and a higher production of its toxic metabolites. Conclusion: the results of this study suggest that exposure to BTEX, even in low concentrations, contributes to genotoxic risk to human health.
\end{abstract}

Keywords: occupational health; gas stations; BTEX; comet assay; oxidative stress. 


\section{Introdução}

Contaminações ambientais e ocupacionais relacionadas a postos de combustíveis atingem um grande número de trabalhadores ${ }^{1,2}$ e residentes no entorno dos postos, especialmente as contaminações relacionadas à gasolina, combustível fóssil derivado do petróleo e de grande consumo no Brasil e no mundo ${ }^{3,4}$. A gasolina é uma mistura complexa de frações líquidas leves do petróleo, contendo diversos hidrocarbonetos alifáticos e aromáticos ${ }^{5}$, como benzeno, tolueno, etilbenzeno e xilenos (BTEX), compostos lipossolúveis e tóxicos que agem como depressores do sistema nervoso central e apresentam toxidade mesmo em baixas concentrações ${ }^{6}$. Além disso, dentre os BTEX, o benzeno destaca-se como o principal composto de relevância toxicológica, devido aos seus efeitos à saúde humana, como síndromes mielodisplásticas (SMD) e, principalmente, a seu efeito carcinogênico, como leucemia mieloide aguda (LMA) ${ }^{7-9}$. Com isso, mesmo que as concentrações de benzeno sejam menores que $1 \%$ na gasolina, como estabelecido pela Agência Nacional do Petróleo, Gás Natural e Biocombustíveis (ANP), o estímulo ao consumo de combustíveis fósseis oriundos da cadeia produtiva do petróleo como política de desenvolvimento econômico, faz com que a exposição ao benzeno a partir da gasolina tenha grande influência no âmbito da saúde ambiental e ocupacional ${ }^{10,11}$.

O benzenismo corresponde ao conjunto de sinais e sintomas decorrentes da exposição ao benzeno. Seu diagnóstico, de natureza ocupacional, é eminentemente clínico e epidemiológico, fundamentando-se na história de exposição ocupacional e na observação de sintomas e sinais clínicos e laboratoriais dos expostos $^{12,13}$. O mecanismo de ação da toxicidade hematopoiética do benzeno ainda permanece em grande parte desconhecido, tanto no desenvolvimento de citopenias periféricas quanto no processo leucogênico da LMA ${ }^{14,15}$. Meek e Klaunig ${ }^{14}$ descreveram uma etapa crítica, relacionada à exposição ao benzeno, que inclui necessariamente um dano oxidativo ao DNA e às macromoléculas celulares importantes, induzindo a mutações e à proliferação clonal das células mutadas. Evidências indicam que os metabólitos do benzeno podem interferir no ciclo celular, induzir apoptose de células precursoras do sistema hematopoiético e alterar importantes vias de sinalização celular, resultando em citotoxicidade $^{15,16}$. Com isso, espécies reativas de oxigênio (EROs), por intermédio de danos oxidativos no DNA (quebras, formação de adutos), parecem estar associadas à exposição ao benzeno e ao aparecimento de seus efeitos, sendo necessários indicadores sensíveis no monitoramento biológico de populações expostas, como o ensaio cometa e outros indicadores de genotoxicidade. Essas espécies reativas podem gerar dano celular, inclusive no material genético, e, dessa forma, os indicadores de estresse oxidativo e o ensaio cometa têm relação direta na avaliação do potencial de dano derivado desse tipo de exposição ${ }^{17}$. Entre os indicadores biológicos de efeito estão as enzimas catalase (CAT) e glutationa $S$-transferase (GST), que correspondem a fatores de proteção para o estresse oxidativo. A CAT atua na degradação de espécies reativas de oxigênio (EROs) e a GST, enzima de biotransformação de fase II, conjuga a glutationa na molécula do benzeno pela ligação com o grupamento tiol, favorecendo o processo de eliminação do benzeno pelo organismo ${ }^{17}$.

O ensaio cometa, também conhecido como SingleCell Gel (SCG) ou Single-Cell Gel Electrophoresis (SCGE), é um teste de genotoxicidade utilizado na detecção de lesões genômicas, que, após serem processadas pelo aparato enzimático celular de reparo do DNA, podem ser corrigidas ou levadas a mutações e danos cromossômicos ${ }^{18,19}$. Uma vez que danos no DNA são frequentemente célula- e tecido-específicos, uma técnica como a do ensaio cometa, que permite a detecção de danos e seus reparos em uma única célula ou em determinada subpopulação celular, é de extrema relevância para a avaliação da genotoxicidade de diferentes compostos ${ }^{18,19}$. Sendo assim, o ensaio cometa possui amplas aplicações, como testes de genotoxicidade in vitro e in vivo, no biomonitoramento ambiental e no monitoramento populacional humano ${ }^{20}$. A aplicação do ensaio cometa no monitoramento populacional humano objetiva avaliar o nível dos danos ao DNA provocados por exposição a compostos tóxicos, estudar os efeitos ou fatores que contribuem para o aparecimento de doenças e investigar variações individuais, como a capacidade de reparo do DNA ou resistência antioxidante ${ }^{18}$.

No Brasil, estudos sobre avaliação toxicológica de trabalhadores de postos de combustíveis com monitoramento biológico ainda são insuficientes e escassos frente à demanda desses trabalhadores e à real situação de risco em que se encontram. De acordo com Moura-Correa et al. ${ }^{21}$, a exposição ocupacional relacionada a postos de combustíveis atinge 184.733 frentistas distribuídos em 39.450 postos de revenda de combustíveis em todo o país. Até o presente momento, estudos sobre genotoxicidade com trabalhadores de postos de combustíveis brasileiros foram publicados por Benites et al. ${ }^{22}$, Moro et al. ${ }^{17}$, Rosa et al. ${ }^{23}$, Trevisan et al. ${ }^{24}$, Santiago et al..$^{25}$, Mitri et al. ${ }^{26}$, Lacerda et al. ${ }^{27}$.

Moro et al. ${ }^{17}$ avaliaram a exposição ao BTEX empregando ensaio cometa, micronúcleo e indicadores de estresse oxidativo (GSH, SOD, CAT e GST), e encontraram danos maiores no material genético de trabalhadores expostos em comparação ao grupo 
controle. Entretanto, comparações de indicadores de genotoxicidade e estresse oxidativo entre trabalhadores de postos de combustíveis com diferentes níveis de concentração ambiental ainda não foram realizadas. Dessa forma, este artigo tem como objetivo avaliar os danos genotóxicos relacionados à exposição ocupacional ao BTEX em trabalhadores de diferentes postos de combustíveis da Zona Norte do município do Rio de Janeiro, por meio da técnica de ensaio cometa, da análise dos níveis de enzimas do estresse oxidativo (CAT e GST) e da determinação analítica dos BTEX no ar.

\section{Metodologia}

Este artigo corresponde a um estudo transversal, cuja seleção dos postos de combustíveis ocorreu de forma conveniente, realizada juntamente com o Sindicato dos Empregados em Postos de Serviços de Combustíveis e Derivados de Petróleo do Estado do Rio de Janeiro (Sinpospetro-RJ) a partir do cadastro dos postos de combustíveis do município do Rio de Janeiro. Segundo dados fornecidos pelo Sinpospetro-RJ, existem 3.080 postos revendedores de combustíveis no estado do Rio de Janeiro, sendo 1.108 localizados no município do Rio de Janeiro. De acordo com a Secretaria Municipal de Urbanismo, o município do Rio de Janeiro é dividido em cinco grandes áreas de planejamento subdivididas em regiões administrativas (RA) geograficamente delimitadas por seus respectivos bairros ou regiões de favelas. De forma conveniente, devido à proximidade, foram selecionadas as RA VII, VIII, IX, X e XIII como área de estudo. Posteriormente, para cada RA, foi sorteado um bairro (Bonsucesso, São Cristóvão, Tijuca, Vila Isabel e Lins de Vasconcelos) e, em seguida, para cada bairro foi sorteado um posto. Os critérios para a seleção foram a acessibilidade do posto, seu consentimento em participar do estudo e sua regulamentação.

Foram incluídos na pesquisa trabalhadores de ambos os sexos, com idade superior a 18 anos. O estudo foi aprovado pelo Comitê de Ética em Pesquisa da ENSP/Fiocruz sob o protocolo CAAE0021.0.031.000-10. Todos os proprietários dos postos foram contactados previamente, autorizaram a pesquisa e assinaram os devidos termos de anuência. Além disso, a aplicação do questionário e as coletas ambientais e biológicas foram realizadas no local de trabalho, sempre que possível em ambiente privado, buscando-se minimizar possíveis influências na coleta de dados.

O questionário, aplicado individualmente, continha questões abertas e fechadas, relativas a idade, sexo, histórico de exposição, tempo de trabalho, tempo na função exercida, consumo de álcool e fumo e características do perfil sociodemográfico.

\section{Avaliação ambiental}

A avaliação ambiental foi realizada em cada posto por meio da determinação das concentrações de BTEX no ar do ambiente de trabalho por um período máximo de três meses entre a primeira e a última coleta. As amostras de ar foram coletadas em cartuchos de carvão ativo da marca SKC (Anasorb CSC SKC - 226-01 com leitos de 100 e 50 mg) específicos para BTEX, com auxílio de bombas coletoras de ar SKC (PCXR4) calibradas para vazão de 1,0 L min ${ }^{-1}$. As amostras foram extraídas com 1,0 mL de diclorometano a $-20{ }^{\circ} \mathrm{C}$ e analisadas por Cromatografia Gasosa com Detector Seletivo de Massas (CG-DSM) em um equipamento Varian 450GC MS22028. Os pontos de amostragem foram posicionados a $1,5 \mathrm{~m}$ de altura do solo na área de circulação dos trabalhadores envolvidos no estudo, próximos às bombas de combustíveis, sendo o ar coletado durante um período médio de 40 minutos por amostra. Tanto o tempo de duração da amostragem quanto a sua vazão foram validados anteriormente por Corrêa et al. ${ }^{28} \mathrm{e}$ utilizados neste estudo.

É importante ressaltar que a eficácia da amostragem foi testada por meio da análise de BTEX no leito principal e no leito secundário dos cartuchos, tendo como critério a quantidade de BTEX no leito secundário permanecer inferior a $5 \%$ da quantidade contida no leito primário, garantindo a sua não saturação. O número de amostras coletadas por dia de avaliação ambiental variou entre um e três de acordo com o tamanho do posto. Em cada posto, buscou-se contemplar os períodos de trabalho da manhã e da tarde, com avaliações ambientais feitas em quatro dias diferentes e em horários alternados, com a finalidade de se ter uma amostragem mais representativa das condições ambientais dos postos ${ }^{29}$. Além disso, a dispersão dos BTEX no ambiente ao redor dos postos de combustíveis também foi avaliada. Pontos posicionados a aproximadamente 200 metros de distância das bombas de combustível da amostragem, seguindo a direção do vento, foram utilizados como controle. Para análise da dispersão, amostras diárias foram coletadas em cada um dos postos durante os quatro dias de avaliação, seguindo os mesmos critérios descritos anteriormente.

\section{Avaliação biológica}

A avaliação biológica foi realizada mediante análise dos indicadores biológicos de genotoxicidade e estresse oxidativo. A avaliação da genotoxicidade se deu por meio da análise de ensaio cometa; e a avaliação dos parâmetros enzimáticos do estresse oxidativo 
pela determinação das atividades das enzimas CAT e GST. As amostras de sangue total foram coletadas em tubos a vácuo com EDTA (ácido etilenodiaminotetracético) para a realização de hemograma completo, e com heparina para as análises de ensaio cometa, CAT e GST. As amostras coletadas foram transportadas em recipiente adequadamente refrigerado até os locais de análise.

\section{Ensaio cometa}

Alíquotas de $5 \mu \mathrm{L}$ de sangue total foram misturadas homogeneamente a $120 \mu \mathrm{L}$ de agarose de baixo ponto de fusão, sendo sequencialmente adicionadas sobre uma lâmina previamente revestida com agarose de ponto de fusão normal. As lâminas foram imersas em solução de lise celular por 24 horas. Após essa etapa, as lâminas foram deixadas por 20 minutos em tampão alcalino e, posteriormente, submetidas a eletroforese sob as condições fixadas em $25 \mathrm{~V}$ e $300 \mathrm{~mA}$ por $20 \mathrm{minu}-$ tos. Em seguida, as lâminas foram neutralizadas com posterior fixação em etanol PA e secagem. Para revelação, as lâminas foram coradas com prata [Ag] e visualizadas em microscópio visível com aumento de 400x. Um total de 100 nucleóides (50 por lâmina) foram analisados por classificação visual, de acordo com o comprimento da cauda. A classificação foi realizada em 5 categorias $(0,1,2,3,4),(0)=$ menor dano e (4) = maior dano, sendo contabilizado o total de Unidades Arbitrárias (UA) por amostra. O total de UA variou entre 0 e 400 para cada amostra individual.

\section{Catalase (CAT)}

A atividade da enzima CAT foi determinada em sangue total empregando $\mathrm{H}_{2} \mathrm{O}_{2}$ como substrato pelo método espectrofotométrico de Aebi (1984) ${ }^{30}$, que se baseia na quantificação da decomposição de $1 \mu \mathrm{mol}$ de $\mathrm{H}_{2} \mathrm{O}_{2} / \mathrm{min}$, monitorada em um comprimento de onda de $240 \mathrm{~nm}$ por 15 segundos.

\section{Glutationa S-transferase (GST)}

A atividade da enzima GST foi determinada em sangue total, empregando 1-cloro-2,4-dinitrobenzeno e glutationa reduzida como substrato pelo método espectrofotométrico de Habig (1981) ${ }^{31}$, que se baseia na quantificação da formação de $1 \mu \mathrm{mol}$ do complexo analito GS-DNB/min, monitorada em um comprimento de onda de $340 \mathrm{~nm}$ por 60 segundos.

\section{Análise estatística}

A variabilidade dos dados da avaliação ambiental inerente à dispersão dos BTEX no ar foi examinada estatisticamente pelo teste $t$ de Student, com intervalo de confiança de $95 \%{ }^{32}$. Algumas amostras apresentaram concentrações superiores de BTEX, pois durante a avaliação ambiental presenciou-se a atividade de abastecimento dos tanques subterrâneos em três postos de combustíveis avaliados. Esses resultados foram analisados separadamente, pois representam momentos de atividades distintas daquelas comumente exercidas pelos trabalhadores.

Na análise descritiva, foram calculadas médias e desvios-padrão das variáveis contínuas (concentração de BTEX, idade, tempo de trabalho em postos de combustíveis, tempo de trabalho na atual função, ensaio cometa, CAT e GST) e frequência percentual de distribuição das variáveis categóricas (sexo, função, consumo de álcool e hábito de fumar). A normalidade da distribuição das variáveis contínuas foi testada por meio do teste Kolmogorov-Smirnov com um nível de significância de 5\%. Para comparação de variáveis com distribuição normal, foram utilizados os testes paramétricos $t$ de Student ou ANOVA e para variáveis com distribuição não normal empregaram-se os testes não paramétricos Mann-Whitney ( $\boldsymbol{U}$ ) ou Kruskal-Wallis $(\boldsymbol{H})$. Testes de correlação de Person (r) e de Spearman (rho) foram realizados para as variáveis contínuas com distribuição normal e não normal, respectivamente. As variáveis sexo e idade serviram como variáveis de controle. Os dados foram analisados com auxílio do programa SPSS for Windows versão 20.0.

\section{Resultados}

Participaram do estudo 97 trabalhadores oriundos de 5 postos de combustíveis localizados nos bairros de Bonsucesso, São Cristóvão, Tijuca, Vila Isabel e Lins de Vasconcelos, selecionados das RA VII, VIII, IX, X e XIII do município do Rio de Janeiro. Os resultados da avaliação ambiental, que correspondem às concentrações de BTEX nas amostras de ar coletadas nos cinco postos de combustíveis, são apresentados na Tabela 1 em ordem crescente de concentração do benzeno.

As concentrações de benzeno no ar atmosférico foram menores nos Postos 1 e 2 em comparação aos outros postos de combustíveis. Para as concentrações de tolueno, etilbenzeno e xilenos, somente o Posto 1 apresentou diferença estatística quando comparado aos Postos 2, 3, 4 e 5. Em todos os postos, os resultados dos pontos de medição a 200 metros da área de circulação dos trabalhadores apresentaram concentrações de BTEX menores comparadas às concentrações dos pontos de amostragem próximos às bombas de combustível (Tabela 1). Os resultados dos cinco pontos de amostragem referentes à atividade de abastecimento dos tanques subterrâneos, presenciada durante a avaliação ambiental em três postos 
de combustíveis, estão apresentados separadamente na Tabela 2.

As características sociodemográficas são apresentadas na Tabela 3. A amostra do estudo foi composta por $72 \%$ de homens e $28 \%$ de mulheres, com idade média de 40 e 32 anos, respectivamente, não havendo diferença estatística por meio do teste $t$ de Student. A maior parte da população foi composta por frentistas $(45,4 \%$ homens e $40,0 \%$ mulheres). A maioria dos entrevistados relatou fazer uso de bebida alcoólica $(69,7 \%$ dos homens e $58,3 \%$ das mulheres) e não fumar $(59,1 \%$ dos homens e $66,6 \%$ das mulheres). Não foi relatada a utilização de nenhum equipamento de proteção individual ou coletiva durante a jornada de trabalho, inclusive durante o recebimento de combustíveis e os testes de qualidade, atividades de maior exposição.

Os resultados das análises biológicas (ensaio cometa, CAT e GST) e dados ocupacionais (tempo de trabalho em postos de combustíveis e tempo de trabalho na atual função) foram comparados entre os diferentes postos de combustíveis e são apresentados na Tabela 4.

Os resultados das análises biológicas foram comparados entre os grupos masculino e feminino, sendo encontrada diferença estatisticamente significativa para os resultados de CAT. Essa diferença entre os sexos, entretanto, não foi observada para a atividade da enzima GST e nem para os danos no DNA, avaliados por ensaio cometa. Além disso, a totalidade dos trabalhadores do grupo masculino apresentou média diferente do grupo feminino para tempo de trabalho em postos de combustíveis. Da mesma forma, foi encontrada uma diferença significativa das médias do tempo de trabalho na atual função entre os grupos masculino e feminino. Essa diferença estatística de médias dos dados ocupacionais também foi observada entre os grupos masculino e feminino do Posto 2. Não foi observada diferença significativa nas médias de idade dos trabalhadores entre os diferentes postos de combustíveis, tanto para o grupo masculino quanto para o feminino.

Tabela 1 Resultados da avaliação ambiental nos postos de combustíveis no município do Rio de Janeiro, em 2012. Concentrações médias de BTEX das amostras de ar coletadas

\begin{tabular}{|c|c|c|c|c|c|c|c|c|c|c|}
\hline \multirow{2}{*}{$\begin{array}{l}\begin{array}{l}\text { Postos } \\
\text { avaliados }\end{array} \\
\text { Pontos de } \\
\text { medição }\end{array}$} & \multicolumn{2}{|c|}{ Posto 1} & \multicolumn{2}{|c|}{ Posto 2} & \multicolumn{2}{|c|}{ Posto 3} & \multicolumn{2}{|c|}{ Posto 4} & \multicolumn{2}{|c|}{ Posto 5} \\
\hline & $A$ & $D$ & $A$ & $D$ & $A$ & $D$ & $A$ & $D$ & $A$ & $D$ \\
\hline$N$ & 16 & 4 & 17 & 4 & 4 & 3 & 14 & 4 & 15 & 3 \\
\hline $\begin{array}{l}\text { Benzeno } \\
\left(\mu \mathrm{g} \mathrm{m}^{-3}\right)\end{array}$ & $6,4(2,3)^{3 * T}$ & $3,5(2,0)^{\mathrm{T}}$ & $27,2(12,1)^{\mathfrak{E T}}$ & $1,8(25,6)^{\mathrm{T}}$ & $373,7(186,9)^{* * 1}$ & $60,9(37,5)^{\uparrow}$ & $452,8(358,0)^{* \pm T}$ & $23,6(50,0)^{\mathrm{T}}$ & $492,5(180,7)^{* \text { *1T }}$ & $75,6(15,3)^{\mathrm{P}}$ \\
\hline $\begin{array}{l}\text { Tolueno } \\
\left(\mu \mathrm{g} \mathrm{m}^{-3}\right)\end{array}$ & $7,5(3,8)^{*}$ & $4,3(2,3)$ & $97,1(39,7)^{* 1}$ & $8,5(12,0)^{\mathrm{T}}$ & $101,7(63,0)^{* \mathrm{~F}}$ & $14,2(10,0)^{\mathrm{T}}$ & $92,3(39,7)^{*}$ & $10,1(13,8)^{\mathrm{T}}$ & $110,5(29,6)^{* \top 1}$ & $18,1(6,1)^{\mathrm{T}}$ \\
\hline $\begin{array}{l}\text { Etilbenzeno } \\
\left(\mu \mathrm{g} \mathrm{m}^{-3}\right)\end{array}$ & $3,2(1,6)^{*}$ & $1,5(1,0)$ & $24,4(14,6)^{* T}$ & $1,3(3,7)^{\mathrm{T}}$ & $32,5(12,9)^{* \top}$ & $4,3(3,1)^{\mathrm{T}}$ & $32,2(12,7)^{*{ }^{\top}}$ & $3,3(4,4)^{\mathrm{T}}$ & $41,8(18,2)^{*}{ }^{*}$ & $6,0(1,4)^{\mathrm{T}}$ \\
\hline $\begin{array}{l}\text { Xilenos } \\
\left(\mu \mathrm{g} \mathrm{m}^{-3}\right)\end{array}$ & $9,1(2,2)^{*}$ & $4,6(2,9)$ & $72,9(46,9)^{* * 1}$ & $3,1(5,8)^{\mathrm{T}}$ & $102,6(42,8)^{* \top}$ & $10,3(6,2)^{\Phi}$ & $96,1(41,7)^{* 1}$ & $5,6(9,0)^{\mathrm{T}}$ & $132,2(40,1)^{* \top}$ & $14,0(3,1)^{\mathrm{T}}$ \\
\hline
\end{tabular}

Resultados expressos em média ponderada (desvio-padrão) com tempo de amostragem de 40 minutos. $N=$ número total de amostras; $\mathrm{A}=$ ponto de medição na área de circulação do posto de combustível e D = ponto de medição a $200 \mathrm{~m}$ da área de circulação do posto de combustível. Comparação das médias das concentrações de BTEX entre A e D por posto de combustível, utilizando teste $t$ de Student, considerando $p=p$-valor ( $p$-valor), [T $p<0.05]$, sendo T referente à diferença estatística entre os pontos de medição A e D. Comparação das médias das concentrações de BTEX de A e D entre os postos de combustíveis, utilizando teste ANOVA, considerando $p=p$-valor ( $\mathrm{p}$-valor), ["£ $p<0.05]$, sendo * referente à diferença estatística em relação ao Posto 1; $£$ referente à diferença estatística em relação ao Posto 2

Tabela 2 Resultados da avaliação ambiental nos postos de combustíveis no município do Rio de Janeiro em 2012. Concentrações de BTEX das amostras coletadas durante a atividade de abastecimento dos tanques subterrâneos

\begin{tabular}{lccccc}
\hline \multicolumn{1}{c}{ Postos avaliados } & \multicolumn{1}{c}{ Posto 1 } & & Posto 3 & & Posto 4 \\
\hline \multicolumn{1}{c}{ Amostras } & 1 & 2 & 3 & 4 & 5 \\
\hline Benzeno $\left(\mu \mathrm{g} \mathrm{m}^{-3}\right)$ & 19,1 & 21,9 & 1244,5 & 1036,8 & 991,2 \\
Tolueno $\left(\mu \mathrm{g} \mathrm{m}^{-3}\right)$ & 33,9 & 15,2 & 192,3 & 165,6 & 264,8 \\
Etilbenzeno $\left(\mu \mathrm{g} \mathrm{m}^{-3}\right)$ & 33,0 & 12,1 & 150,6 & 110,8 & 252,3 \\
Xilenos $\left(\mu \mathrm{g} \mathrm{m}^{-3}\right)$ & 10,9 & 2,5 & 47,9 & 37,5 & 95,5 \\
\hline
\end{tabular}

Resultados das concentrações com tempo de amostragem de 40 minutos 
Tabela 3 Características sociodemográficas da população do estudo

\begin{tabular}{|c|c|c|c|c|}
\hline \multirow{2}{*}{ Variáveis } & \multicolumn{2}{|c|}{ Homens $(N=70)$} & \multicolumn{2}{|c|}{ Mulheres $(N=27)$} \\
\hline & $N$ & $\%$ & $N$ & $\%$ \\
\hline \multicolumn{5}{|l|}{ Função } \\
\hline Administrativa & 12 & 18,2 & 15 & 60.0 \\
\hline Frentista & 30 & 45,4 & 10 & 40.0 \\
\hline Borracheiro & 7 & 10,6 & 0 & 0.0 \\
\hline Lavador & 17 & 25,8 & 0 & 0.0 \\
\hline \multicolumn{5}{|l|}{ Consumo de álcool } \\
\hline Não consomem & 9 & 13,6 & 0 & 0.0 \\
\hline Consomem & 46 & 69,7 & 14 & 58.3 \\
\hline Pararam o consumo & 11 & 16,7 & 10 & 41.7 \\
\hline \multicolumn{5}{|l|}{ Hábito de fumar } \\
\hline Não fumante & 39 & 59,1 & 16 & 66.6 \\
\hline Fumante & 15 & 22,7 & 4 & 16.7 \\
\hline Ex-fumante & 12 & 18,2 & 4 & 16.7 \\
\hline Idade & \multicolumn{2}{|c|}{$40(11)^{\Phi}$} & \multicolumn{2}{|c|}{$32(8)^{\mathrm{T}}$} \\
\hline
\end{tabular}

$N=$ número total de casos. Idade expressa em média (desvio padrão). Comparação das médias de idade entre homens e mulheres, utilizando teste $t$ de Student, considerando $p=p$-valor ( $p$-valor), [T $p<0.05]$, sendo T referente à diferença estatística entre homens e mulheres

Os dados ocupacionais "tempo de trabalho em postos" e "tempo de trabalho na atual função" apresentaram diferença significativa entre o Posto 2 e os Postos 1, 4 e 5, para o grupo masculino. A média de tempo de trabalho em postos de combustíveis também foi estatisticamente diferente entre os Postos 3 e 5 no grupo masculino. No grupo feminino, foi encontrada diferença significativa de tempo de trabalho na atual função entre o Posto 5 e os Postos 1 e 4 (Tabela 4).

Os resultados das análises biológicas foram comparados entre os diferentes postos de combustíveis. Os trabalhadores do sexo masculino dos Postos 1 e 2, com as menores concentrações de benzeno no ar atmosférico, apresentaram danos no material genético significativamente maiores quando comparados aos trabalhadores de mesmo sexo do Posto 3, o terceiro em maior concentração de benzeno. Além disso, os Postos 3 e 5 também apresentaram diferença significativa para o teste de ensaio cometa, sendo o dano no material genético maior no Posto 5. No grupo feminino, uma diferença significativa também pode ser observada entre o Posto 2 e os Postos 3 e 4; e entre o Posto 5 e os Postos 3 e 4. Essas mesmas diferenças entre os postos se mantêm quando somados os grupos masculino e feminino. A oscilação dos resultados de genotoxicidade por ensaio cometa pode ser melhor visualizada por meio das classificações dos danos no DNA, que precedem o resultado final expresso em unidades arbitrárias (UA).

É possível observar, tanto no grupo de homens (Figura 1a) quanto no grupo de mulheres (Figura 1b), um aumento da classificação do dano 0 e uma diminuição da classificação do dano 1, ambos acentuados no Posto 3 e discrepantes dos Postos 1, 2 e 5. Com relação às enzimas do estresse oxidativo, apenas a CAT apresentou diferença significativa na comparação dos Postos 1 e 2 com os Postos 3, 4 e 5, no grupo masculino. No grupo feminino, essa diferença se mantém entre o Posto 3 e os postos 1, 4 e 5. Para o total da população, ou seja, juntando-se os grupos masculino e feminino, essa diferença entre os Postos permanece somente na comparação entre o Posto 2 com os Postos 3, 4 e 5.

Os resultados das análises dos indicadores biológicos, assim como os dados ocupacionais, também foram comparados entre as diferentes funções, classificadas como administrativa, frentista, borracheiro e lavador, e estão apresentados na Tabela 5. A função administrativa foi considerada a de menor exposição aos solventes da gasolina, e as funções de frentista e borracheiro consideradas as de maior exposição, de acordo com as observações das atividades de trabalho das respectivas funções.

A função de trabalho de frentista apresentou diferença entre os grupos masculino e feminino para todos os indicadores biológicos e dados ocupacionais. A atividade enzimática da CAT também apresentou diferenças estatísticas entre os sexos na função administrativa. Além disso, as funções de trabalho foram comparadas com relação ao sexo separadamente. Dos indicadores biológicos, o ensaio cometa apresentou diferença entre as funções administrativa e frentista no grupo feminino; a CAT, entre 
as funções administrativa e lavador no grupo masculino. Entretanto, para o conjunto total da população de homens e mulheres, somente a CAT apresentou diferença entre a função administrativa e as funções de frentista e lavador, e entre as funções frentista e lavador. Dos dados ocupacionais, o tempo de trabalho na atual função apresentou diferença entre as funções administrativa e borracheiro somente no grupo masculino. Essa diferença se mantém quando agrupados os trabalhadores homens e mulheres. Além disso, o total da população também apresentou diferença nas médias de tempo de trabalho em postos de combustíveis entre a função administrativa e as funções frentista e borracheiro.

Por fim, os resultados dos indicadores biológicos e os dados ocupacionais foram analisados quanto à linearidade. O teste de ensaio cometa apresentou correlação negativa, por Spearman, com a atividade enzimática da GST ( $p=0,026, R=-0,228$ ) e com o tempo de trabalho na atual função ( $p=0,031$, $R=-0,232$ ). A atividade da enzima GST apresentou uma correlação positiva, por Pearson, com o tempo de trabalho na atual função $(p=0,011, R=+0,276)$ e negativa com ensaio cometa $(p=0,0013, R=-0,256)$.

Tabela 4 Comparação dos resultados dos indicadores biológicos e dos dados ocupacionais dos trabalhadores entre os diferentes postos de combustíveis

\begin{tabular}{|c|c|c|c|c|c|c|c|}
\hline & Sexo & Posto 1 & Posto 2 & Posto 3 & Posto 4 & Posto 5 & $\begin{array}{l}\text { População } \\
\text { global }\end{array}$ \\
\hline \multirow{3}{*}{$\mathrm{N}$} & $M$ & 13 & 9 & 23 & 13 & 13 & 71 \\
\hline & $\mathrm{F}$ & 4 & 13 & 3 & 3 & 4 & 27 \\
\hline & $M+F$ & 17 & 21 & 26 & 16 & 17 & 97 \\
\hline \multirow{3}{*}{$\begin{array}{l}\text { Ensaio cometa } \\
\text { (UA) }\end{array}$} & $\mathrm{M}$ & $21(15)^{*}$ & $20(5)^{£}$ & $13(15)^{* £ o}$ & $16(18)$ & $22(15)^{\mathrm{o}}$ & $17(15)$ \\
\hline & $\mathrm{F}$ & $1(16)$ & $25(15)^{£}$ & $6(4)^{£ o}$ & $8(3)^{£ \eta}$ & $27(16)^{\text {по }}$ & $20(15)$ \\
\hline & $\mathrm{M}+\mathrm{F}$ & $20(15)^{*}$ & $23(13)^{£}$ & $12(14)^{* \mathrm{fo}_{\mathrm{o}}}$ & $14(16)^{£ \eta}$ & $23(15)^{\text {по }}$ & $18(15)$ \\
\hline \multirow{3}{*}{$\begin{array}{l}\text { Catalase } \\
\text { (KU/g Hb) }\end{array}$} & M & $210(19)^{\top *}$ & $211(13)^{\mathrm{TE}}$ & $195(16)^{\mathrm{I} * \mathrm{f}}$ & $194(18)^{\text {T㓥 }}$ & $195(14)^{\text {T** }}$ & $199(18)^{T}$ \\
\hline & $\mathrm{F}$ & $265(26)^{\Phi *}$ & $252(52)^{\mathrm{T}}$ & $237(48)^{\mathrm{I} * \cdots \mathrm{O}}$ & $255(13)^{\Phi_{1}}$ & $253(25)^{\text {To }}$ & $253(35)^{\text {T }}$ \\
\hline & $M+F$ & $223(32)^{*}$ & $235(44)^{£}$ & $200(20)^{*} \mathcal{E}$ & $206(30)^{£}$ & $209(28)^{£}$ & $213(33)$ \\
\hline \multirow{3}{*}{$\begin{array}{l}\text { GST } \\
(\mathrm{U} / \mathrm{g} \mathrm{Hb})\end{array}$} & M & $7,9(1,3)$ & $7,2(1,2)$ & $9,1(2,1)$ & $7,8(2,1)$ & $7,2(1,5)$ & $8,1(1,9)$ \\
\hline & $\mathrm{F}$ & $8,1(1,8)$ & $6,1(2,2)$ & $10,2(2,5)$ & $7,4(2,7)$ & $6,9(2,3)$ & $7,2(2,4)$ \\
\hline & $M+F$ & $8,0(0,1)$ & $6,6(1,9)$ & $9,2(2,1)$ & $7,7(2,1)$ & $7,2(1,7)$ & $7,9(2,1)$ \\
\hline \multirow{3}{*}{$\begin{array}{l}\text { Tempo de trabalho em } \\
\text { posto (anos) }\end{array}$} & M & $12(13)^{*}$ & $27(6)^{\top * \mathcal{E}}$ & $18(12)$ & $14(11)^{£}$ & $14(9)^{£}$ & $16(11)^{\mathrm{T}}$ \\
\hline & $\mathrm{F}$ & $6(3)$ & $10(8)^{\Phi}$ & $13(11)$ & $9(13)$ & $5(6)$ & $9(8)^{\Phi}$ \\
\hline & $\mathrm{M}+\mathrm{F}$ & $11(12)$ & $17(10)$ & $18(12)$ & $13(11)$ & $12(9)$ & $14(11)$ \\
\hline \multirow{3}{*}{$\begin{array}{l}\text { Tempo de trabalho na } \\
\text { atual função (anos) }\end{array}$} & M & $8(9)^{*}$ & $16(9)^{\text {T*ध£ }}$ & $14(10)^{\mathrm{o}}$ & $9(8)^{£}$ & $6(7)^{£ o}$ & $11(9)^{\Phi}$ \\
\hline & $\mathrm{F}$ & $3(2)^{*}$ & $4(3)^{T}$ & $13(11)$ & $7(8)^{\mathrm{n}}$ & $1(1)^{* \cdots}$ & $5(6)^{\mathrm{T}}$ \\
\hline & $M+F$ & $7(8)$ & $9(9)$ & $14(11)^{\mathrm{o}}$ & $8(8)$ & $4(6)^{\circ}$ & $9(9)$ \\
\hline
\end{tabular}

Resultados expressos em média (desvio-padrão). $N$ = número total de trabalhadores; $\mathrm{M}$ = Masculino; $\mathrm{F}$ = Feminino; UA = unidade arbitrária; $\mathrm{U}=$ unidade $\left(\mathrm{L} . \mathrm{mol}^{-1} . \mathrm{cm}^{-1}\right) ; \mathrm{Hb}=$ hemoglobina. Comparação das médias dos indicadores (ensaio cometa, CAT, GST, tempo de trabalho em postos e tempo de trabalho na atual função) entre sexo (M e F) por posto de combustível, utilizando teste $t$ de Student para GST e Mann-Whitney para os demais indicadores, considerando $p=p$-valor ( $\mathrm{p}$-valor), [ $\mathrm{T} p<0.05]$, sendo $\mathrm{T}$ referente à diferença estatística entre M e F. Comparação das médias dos indicadores (ensaio cometa, CAT, GST, tempo de trabalho em postos e tempo de trabalho na atual função) entre os postos de combustíveis, utilizando teste ANOVA para GST e teste Kruskal-Wallis para os demais indicadores, considerando $p=p$-valor ( $p$-valor), [* $£$ no $p<0.05$ ], sendo * referente à diferença estatística em relação ao Posto $1 ; €$ referente à diferença estatística em relação ao Posto $2 ; 0$ referente à diferença estatística em relação ao Posto 3; $\eta$ referente à diferença estatística em relação ao Posto 4 
a - Classificação dos danos de DNA no grupo de homens

aposto 1 -Posto 2 -Posto 3 -Posto 4 Posto 5

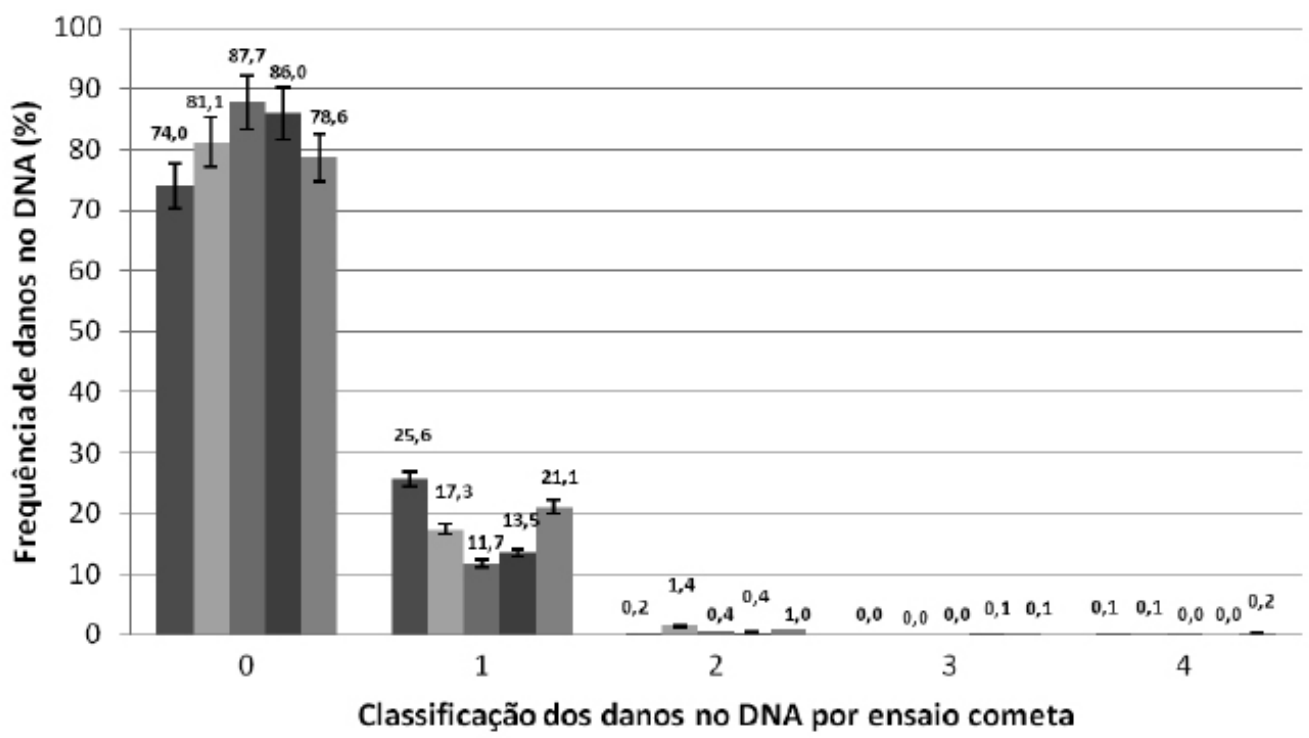

b - Classificação dos danos de DNA no grupo de mulheres

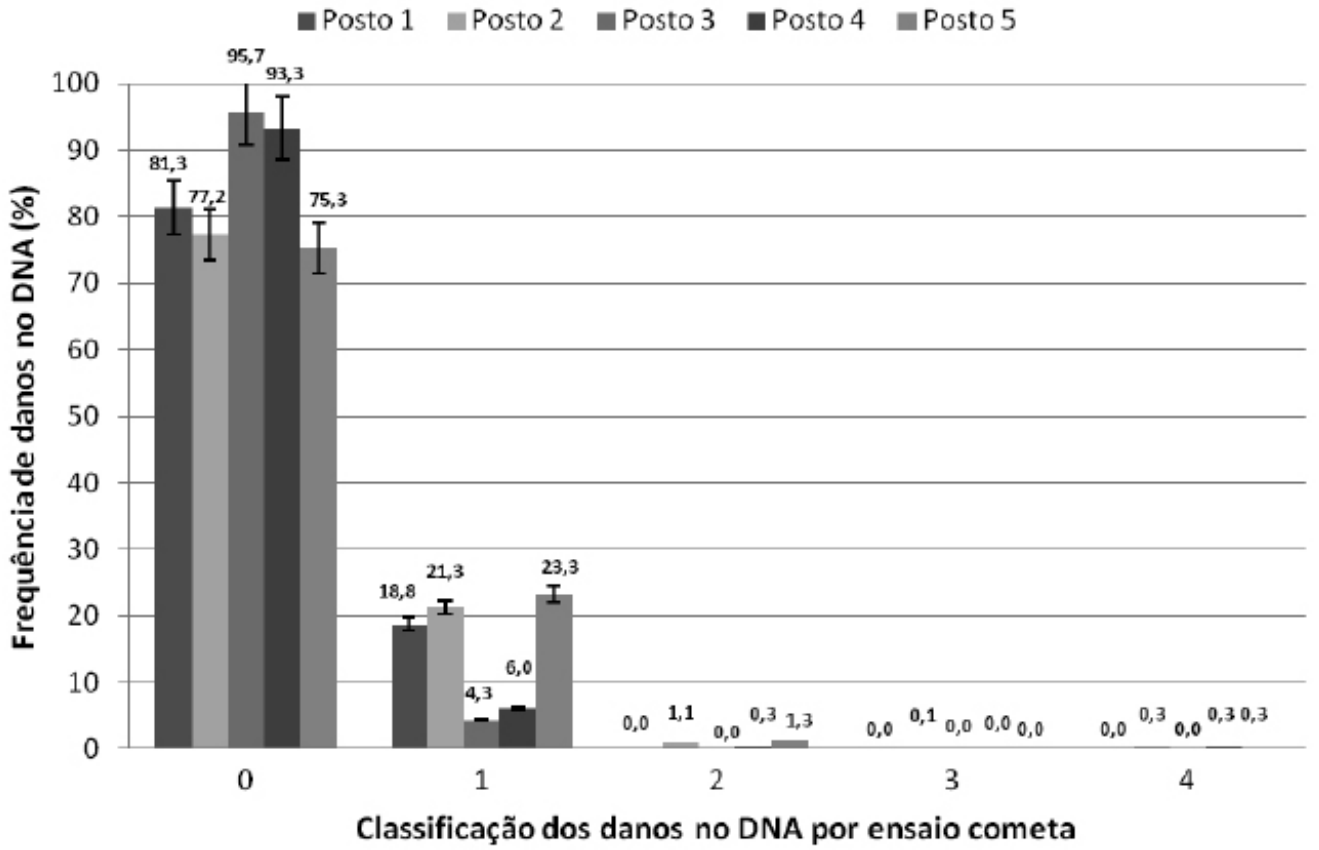

Figura 1 Classificação dos danos de DNA por ensaio cometa entre as populações dos diferentes postos de combustíveis combustíveis para homens (a) e mulheres (b) 
Tabela 5 Comparação dos resultados dos indicadores biológicos e dos dados ocupacionais dos trabalhadores entre as diferentes funções de trabalho

\begin{tabular}{|c|c|c|c|c|c|}
\hline & Sexo & Administrativa & Frentista & Borracheiro & Lavador \\
\hline \multirow{3}{*}{$\mathrm{N}$} & M & 13 & 30 & 7 & 17 \\
\hline & $\mathrm{F}$ & 15 & 10 & 0 & 0 \\
\hline & $M+F$ & 28 & 40 & 7 & 17 \\
\hline \multirow{3}{*}{ Ensaio cometa (UA) } & M & $19(18)$ & $17(15)^{\mathrm{T}}$ & $15(9)$ & $17(16)$ \\
\hline & $\mathrm{F}$ & $15(13)^{*}$ & $30(16)^{\mathrm{T} *}$ & - & - \\
\hline & $M+F$ & $17(15)$ & $20(16)$ & $15(9)$ & $17(16)$ \\
\hline \multirow{3}{*}{ Catalase (KU/g Hb) } & M & $206(17)^{\text {†ै* }}$ & $200(17)^{\mathrm{T}}$ & $208(17)$ & $193(15)^{*}$ \\
\hline & $\mathrm{F}$ & $252(18)^{\Phi}$ & $258(58)^{\Phi}$ & - & - \\
\hline & $M+F$ & $231(30)^{*}$ & $212(38)^{* £}$ & $207(17)$ & $193(15)^{* * £}$ \\
\hline \multirow{3}{*}{ GST (U/g Hb) } & $\mathrm{M}$ & $7,7(2,6)$ & $8,0(1,7)^{\Phi}$ & $8,3(1,6)$ & $8,4(2,0)$ \\
\hline & $\mathrm{F}$ & $7,7(2,4)$ & $6,3(2,8)^{\Phi}$ & - & - \\
\hline & $\mathrm{M}+\mathrm{F}$ & $7,8(2,4)$ & $7,6(2,1)$ & $8,3(1,6)$ & $8,4(2,0)$ \\
\hline \multirow{3}{*}{$\begin{array}{l}\text { Tempo de trabalho em } \\
\text { posto (anos) }\end{array}$} & $M$ & $12(12)$ & $17(10)^{\mathrm{T}}$ & $24(14)$ & $15(11)$ \\
\hline & $\mathrm{F}$ & $9(8)$ & $10(7)^{\mathrm{T}}$ & - & - \\
\hline & $M+F$ & $10(10)^{*}$ & $15(10)^{*}$ & $24(14)^{*}$ & $15(11)$ \\
\hline \multirow{3}{*}{$\begin{array}{l}\text { Tempo de trabalho na atual } \\
\text { função (anos) }\end{array}$} & M & $7(8)^{*}$ & $11(10)^{\mp}$ & $16(9)^{*}$ & $10(9)$ \\
\hline & $\mathrm{F}$ & $6(7)$ & $3(2)^{\mathrm{T}}$ & - & - \\
\hline & $M+F$ & $6(7)^{*}$ & $9(9)$ & $16(9)^{*}$ & $10(9)$ \\
\hline
\end{tabular}

Resultados expressos em média (desvio-padrão); $N$ = número total de trabalhadores; $\mathrm{M}=$ Masculino; $\mathrm{F}=$ Feminino; $\mathrm{UA}=$ unidade arbitrária; $\mathrm{U}=$ unidade $\left(\mathrm{L} \cdot \mathrm{mol}^{-1} \cdot \mathrm{cm}^{-1}\right) ; \mathrm{Hb}=$ hemoglobina; comparação das médias dos indicadores (ensaio cometa, CAT, GST, tempo de trabalho em postos e tempo de trabalho na atual função) entre sexo (M e F) por função de trabalho, utilizando teste $t$ de Student para GST e Mann-Whitney para os demais indicadores, considerando $p=p$-valor ( $\mathrm{p}$-valor), $[\mathrm{T} p<0.05]$, sendo $\Phi$ referente à diferença estatística entre $\mathrm{M}$ e $\mathrm{F}$; comparação das médias dos indicadores (ensaio cometa, CAT, GST, tempo de trabalho em postos e tempo de trabalho na atual função) entre as funções de trabalho, utilizando teste ANOVA para GST e teste Kruskal-Wallis para os demais indicadores, considerando $p=p$-valor ( $p$-valor), [*£ $£<0.05]$, sendo * referente à diferença estatística em relação à função administrativa; $€$ referente à diferença estatística entre as funções frentista e lavador

\section{Discussão}

Neste estudo, os resultados da avaliação ambiental, tanto na área de circulação dos trabalhadores próxima às bombas de abastecimento quanto a 200 metros de distância destas, apresentaram concentrações de BTEX dentro dos valores preconizados pela legislação brasileira, inclusive durante a atividade de abastecimento dos tanques subterrâneos, cuja atividade apresentou os pontos de maior exposição ${ }^{33,34}$. Os Postos 1 e 2 apresentaram as menores concentrações de BTEX no ar atmosférico, o que pode ser explicado pelo fato desses postos estarem localizados em uma área com poucos prédios ao seu redor, o que facilita a dispersão dos vapores de BTEX. Por sua vez, com as maiores concentrações de BTEX, o Posto 5 está localizado em uma área com muitos prédios ao seu redor. Além disso, trata-se de um posto de grande porte, com grande volume de vendas, o que influencia a dispersão dos vapores.
É importante ressaltar que, mesmo com os resultados da avaliação ambiental apresentando concentrações de benzeno abaixo do Valor de Referência Tecnológico de $1 \mathrm{ppm}$ ou 3,19 mg. $\mathrm{m}^{-3}$, estabelecido pela NR 15 (Anexo 13-A) ${ }^{33}$ para setores de atividade com benzeno, tal fato não exclui o risco à saúde humana, pois não existe limite de exposição seguro para substâncias carcinogênicas, como no caso do benzeno. Da mesma forma, para tolueno, xilenos e etilbenzeno, mesmo com concentrações no ar atmosférico dentro dos limites estabelecidos pela NR 15 (460 mg.m ${ }^{-3}$ para tolueno; $340 \mathrm{mg} \cdot \mathrm{m}^{-3}$ para xilenos e etilbenzeno ${ }^{34}$, não há estudos que comprovem a segurança ocupacional e ambiental tanto para a população de trabalhadores de postos de combustíveis quanto para a população do entorno.

Com isso, mesmo com os compostos estando abaixo das concentrações estabelecidas, não se pode descartar a possibilidade de um risco ocupacional e ambiental tanto para a população de trabalhadores quanto para a população em geral, não exposta 
ocupacionalmente, que transita ou reside no entorno dos postos de combustíveis avaliados. O risco da exposição se configura pelo espalhamento dos vapores de BTEX no entorno do estabelecimento em várias direções definidas pela direção do vento e as características do local. Segundo Carrieri et al. ${ }^{35}$, a população em geral se expõe ambientalmente devido à volatilização dos solventes presentes na gasolina oriunda tanto dos postos de combustíveis, durante o abastecimento de tanques e veículos, quanto das emissões veiculares, o que acaba por gerar uma difusão universal.

Considerando a população total de trabalhadores dos postos de combustíveis avaliados, o único indicador biológico que apresentou diferença estatisticamente significativa entre os grupos masculino e feminino foi a atividade enzimática da CAT, juntamente com os dados de tempo de trabalho em posto, tempo de trabalho na atual função e idade. A diferença da CAT entre os grupos masculino e feminino permanece quando os dados da avaliação biológica dos trabalhadores são comparados entre os diferentes postos de combustíveis (Tabela 4) e entre as funções de trabalho (Tabela 5), sendo a atividade enzimática maior no grupo de mulheres. Essa maior atividade da CAT no grupo feminino não parece ter relação com as diferentes concentrações de BTEX no ar atmosférico dos postos, pois essa diferença significativa se mantém em todos os postos estudados e nas funções de trabalho. Contrariamente aos resultados observados no atual estudo, Góth ${ }^{36}$ encontrou média da atividade da CAT menor no grupo de mulheres quando comparada ao grupo de homens. Um fator importante que deve ser levado em consideração é o fato de mulheres possuírem tendência a ter taxas cardiovascular, respiratória e metabólica menor quando comparadas aos homens, tornando-as menos vulneráveis aos efeitos das $\mathrm{EROs}^{37}$.

Além disso, uma diferença significativa foi observada entre os postos de menor concentração de BTEX (1 e 2) e os postos de maior concentração (3, 4 e 5), sendo a atividade da CAT menor nestes últimos. Essa depleção da atividade da CAT pode ter ocorrido devido à saturação enzimática com o aumento da exposição aos BTEX e, consequentemente, de seus metabólitos. Entretanto, estudos em humanos comparando a atividade enzimática da CAT de populações expostas e entre homens e mulheres, além de escassos, possuem resultados controversos e não conclusivos, necessitando-se ainda de mais estudos nessa área ${ }^{36-38}$.

Com relação aos outros indicadores biológicos, além da atividade enzimática da CAT, o ensaio cometa também foi sensível às variações de concentração de BTEX nos diferentes postos de combustíveis. Trabalhadores masculinos alocados nos
Postos 1 e 2 , expostos às menores concentrações de benzeno no ar identificadas neste estudo, apresentaram maiores danos no material genético quando comparados aos trabalhadores masculinos alocados no Posto 3, um dos postos com maior concentração de benzeno no ar. Por sua vez, esses mesmos trabalhadores do Posto 3 apresentaram dano no material genético estatisticamente menores quando comparados aos trabalhadores do Posto 5. Essa mesma oscilação nos resultados do teste de ensaio cometa também pode ser observada para o grupo feminino. Esses resultados indicam o efeito genotóxico precoce da exposição ocupacional desses trabalhadores, ou seja, um aumento do dano genotóxico mesmo em menores concentrações, corroborando o fato de o Valor de Referência Tecnológico (1 ppm ou 3,19 mg.m-3) estabelecido para setores de atividade com benzeno não excluir risco à saúde ${ }^{33}$.

É importante ressaltar que trabalhadores do Posto 5, com a maior concentração de benzeno no ar, apresentaram um elevado dano no material genético e uma baixa média de tempo de trabalho na atual função. Esse resultado chama atenção para uma possível influência do tempo recente de trabalho na atual função no aumento do dano genotóxico. Corroborando esse resultado, a análise de correlação apresentou correlação negativa entre o teste de ensaio cometa e o tempo de trabalho na atual função ( $p=0,031, R=-0,232$ ). Quando essa correlação foi controlada pela idade, houve aumento do coeficiente de correlação ( $p=0,009, R=-0,296)$.

Evidências recentes mostram que os seres humanos metabolizam o benzeno de forma mais eficiente em baixas concentrações ambientais do que em altas concentrações, devido a um processo de saturação das enzimas de metabolização. Rappaport et al. ${ }^{39}$, por meio da comparação de modelos cinéticos de duas vias metabólicas do benzeno, sugerem maior risco de leucemia em baixos níveis ambientais de exposição. Confirmando essa suposição, Vlaanderen et $\mathrm{al}^{40}$ realizaram um estudo de metanálise por metarregressão com o objetivo de avaliar a curva dose-resposta benzeno e risco de leucemia, sendo indicado pelo modelo uma forma supralinear da curva dose-resposta na região de baixas doses de exposição ao benzeno. Provavelmente, esse resultado de maior risco de leucemia em baixas doses ocorre pelo benzeno ser mais eficientemente metabolizado em baixas concentrações, aumentando a produção de seus metabólitos reativos, que são hematotóxicos ${ }^{41-44}$.

Dessa forma, uma possível explicação para os resultados de ensaio cometa encontrados neste estudo é a suposição de que trabalhadores dos postos de combustíveis com as concentrações mais baixas de benzeno e menor tempo de trabalho na atual função possam produzir metabólitos hematotóxicos 
do benzeno em maior concentração e, consequentemente, um maior dano ao DNA seria causado pela exposição recente. Além disso, os resultados obtidos neste estudo estão na mesma faixa de resultados que demonstram um maior dano genotóxico em baixas concentrações de benzeno, em razão da forma supralinear da curva dose-resposta a baixas doses.

A influência do tempo na atual função nos resultados observados neste estudo também pode ser explicada pelo fato de que lesões genômicas, após serem processadas pelo aparato enzimático celular de reparo do DNA, podem ser corrigidas, não formando quebras no DNA, o que impossibilitaria que essas lesões fossem observadas no teste de ensaio cometa tradicional empregado neste estudo ${ }^{18-19}$. Dessa forma, trabalhadores expostos a maiores concentrações de benzeno no ar atmosférico, como é o caso do grupo de trabalhadores do Posto 3, podem não ter apresentado maiores danos no DNA devido a menores concentrações dos metabólitos hematotóxicos do benzeno e ao reparo ocorrido no material genômico. Como os danos no DNA apresentados pelo teste de ensaio cometa são extremamente precoces e passíveis ainda de serem reparados, pode-se considerar que os danos evidenciados pelo ensaio cometa antecedem o dano hematológico, como desfecho.

As diferenças dos resultados genotóxicos podem ser melhor observadas quando comparadas às diferentes classificações de danos no DNA por ensaio cometa entre as populações dos diferentes postos de combustíveis. As Figuras 1a e 1b, para os grupos de trabalhadores masculino e feminino, respectivamente, mostram a oscilação da frequência de nucleóides da classe 0 (i.e., sem danos no DNA) e da frequência de nucleóides da classe 1 (com dano no DNA) com o aumento da concentração de benzeno nos postos de combustívelis.

É importante ressaltar que, apesar do benzeno destacar-se como o principal composto de relevância toxicológica presente nos solventes voláteis de postos de combustíveis, o dano no material genômico observado neste estudo não pode ser atribuído exclusivamente ao benzeno, levando-se em consideração a múltipla exposição desses trabalhadores. Além disso, não há estudos que comprovem a segurança ocupacional da múltipla exposição ao BTEX para populações de trabalhadores de postos de combustíveis.

Por fim, a GST corresponde a uma família de enzimas com diferentes localizações celulares, que também auxilia na resposta ao estresse oxidativo com a detoxificação de xenobióticos nocivos pela conjugação do grupamento GSH com substratos eletrofílicos, que podem ser endógenos ou metabólitos de xenobióticos provenientes da primeira etapa (reações de fase I) do processo de metabolização de substâncias químicas realizado pelo organismo ${ }^{45,46}$. A atividade enzimática da GST apresentou correlação negativa com o ensaio cometa $(p=0,026$, $R=-0,228)$ e correlação positiva com o tempo de trabalho na atual função ( $p=0,011, R=+0,276)$. É importante ressaltar que a atividade da GST pode ser influenciada por indução enzimática devido ao longo tempo de metabolização desses compostos ${ }^{46}$. Dessa forma, uma maior atividade da enzima de detoxificação GST pode contribuir para a diminuição das concentrações dos metabólitos reativos do benzeno, protegendo o material genético de danos oxidativos e levando a uma correlação negativa com o ensaio cometa. Entretanto, estudos que relacionam a exposição ao BTEX e a atividade enzimática da GST são poucos e não conclusivos, havendo necessidade de mais estudos nesta área.

Os resultados obtidos dos indicadores biológicos e dos dados ocupacionais dos 97 trabalhadores também foram comparados quanto às diferentes funções de trabalho relatadas: administrativa, frentista, borracheiro e lavador. A função de frentista apresentou diferença significativa entre os grupos masculino e feminino para todos os indicadores biológicos e para os dados ocupacionais. Além disso, no grupo feminino, as duas funções relatadas, que foram administrativa e frentista, apresentaram diferença significativa para o teste de ensaio cometa. Essa diferença observada entre o grupo de mulheres e não observada entre o grupo de homens pode estar relacionada às diferenças nas atividades de função inerentes ao gênero, pois mulheres na função administrativa dificilmente realizam atividades de frentista, o que foi relatado frequentemente para o gênero masculino, fazendo com que os homens na função administrativa se exponham mais que as mulheres.

Com relação ao conjunto total de trabalhadores masculinos e femininos, o único indicador biológico que apresentou diferença entre as funções foi a atividade da CAT, sendo maior na função administrativa e menor nas funções de frentista e lavador. Esse resultado confirma uma diminuição da atividade da CAT com o aumento da exposição. A função de lavador, apesar de teoricamente apresentar uma menor exposição ao BTEX se comparada à função de frentista, possivelmente apresenta atividade laboral com maior frequência respiratória, o que colabora com o aumento da exposição. Entretanto, mais estudos em trabalhadores expostos a BTEX que analisem a atividade enzimática da CAT devem ser realizados.

As atividades que envolvem a exposição dos trabalhadores aos riscos decorrentes da exposição aos solventes presentes nos combustíveis, em especial ao benzeno presente na gasolina, representam grande preocupação para o campo da saúde do trabalhador. Além das atividades relacionadas ao armazenamento 
e manuseio de líquidos inflamáveis serem classificadas como perigosas ${ }^{48}$, a exposição crônica ao benzeno possui importante relevância toxicológica, sendo preconizado o monitoramento ambiental e biológico. Além disso, para a exposição ao benzeno, foi adotado o Valor de Referência Tecnológico (VRT) no lugar do Limite de Tolerância (LT), assumindo-se legalmente que, mesmo estabelecendo um valor ambiental em termos de vigilância sanitária, não se excluiu o risco causado à saúde dos trabalhadores expostos $^{49}$. Nesse contexto, todos os trabalhadores dos postos de combustíveis avaliados são considerados vulneráveis, principalmente os trabalhadores das funções frentista e borracheiro, cujas atividades impõem maior risco de exposição.

Os resultados deste estudo indicam que a exposição ao BTEX, e mais especificamente ao benzeno em baixas concentrações, contribui para o risco genotóxico à saúde humana. Entretanto, como limitação deste estudo, ressalta-se a utilização de um desenho transversal que capturou todas as informações para o trabalho em um mesmo período de tempo, de maneira que não se pode assumir aqui a indicação da causalidade. No entanto, apesar de suas limitações, esse desenho tem sido o mais utilizado em pesquisas com objetivos similares ao deste estudo ${ }^{2,17,23-25}$, não sendo limitada, portanto, a comparabilidade de seus resultados.

\section{Conclusões}

A avaliação ambiental realizada neste estudo identificou concentrações de BTEX dentro dos valores permitidos pela legislação em todos os postos de combustíveis avaliados. Entretanto, os resultados do ensaio cometa apresentaram oscilação com o aumento da concentração de BTEX nos postos de combustíveis avaliados, sendo os danos genéticos maiores em trabalhadores alocados em postos com menores concentrações de benzeno no ar. Uma possível influência do recente tempo de trabalho na atual função nos resultados de danos no material genético também foi observada. Esses resultados da avaliação biológica são coerentes com estudos recentes que indicam uma segunda via metabólica do benzeno e uma relação supralinear na curva dose-resposta para exposição a baixas doses da substância, o que possivelmente acarreta em sua maior metabolização e maior produção de metabólitos tóxicos. Sendo assim, os resultados deste trabalho sugerem que a exposição ao BTEX contribui para o risco genotóxico à saúde humana, mesmo em baixas concentrações. Porém, isso não significa que trabalhadores de postos de combustíveis expostos a maiores concentrações de BTEX no ar não sejam também levados ao adoecimento, havendo necessidade de mais estudos sobre o mecanismo da toxicidade hematopoiética do benzeno e dos demais hidrocarbonetos presentes na gasolina "e outros combustíveis".

Além disso, não se deve descartar a possibilidade de um risco ambiental para a população do entorno dos postos de combustíveis, ainda que as concentrações de BTEX estejam dentro dos limites legais estabelecidos em um raio de aproximadamente $200 \mathrm{~m}$. Por sua vez, mesmo com o benzeno destacando-se como o principal composto de relevância toxicológica em razão de seus efeitos carcinogênicos à saúde humana, o dano no material genético observado neste estudo não pode ser atribuído exclusivamente à substância, levando-se em consideração a múltipla exposição a que os trabalhadores de postos de combustíveis estão submetidos.

Por isso, identificar um biomarcador precoce em relação às alterações hematológicas e sensível em diferentes condições é de grande importância para a saúde do trabalhador. Desse modo, a utilização de técnicas mais sensíveis, que utilizem enzimas endonucleases, capazes de clivar o DNA nos pontos de formação da oxidação, pode ser uma possível abordagem para o monitoramento biológico de populações expostas. Portanto, estudos que contemplem o monitoramento biológico de populações expostas devem continuar sendo realizados, assim como estudos de elucidação dos mecanismos de ação do benzeno e dos demais hidrocarbonetos presentes na gasolina e no organismo humano.

\section{Contribuições de autoria}

Costa-Amaral IC, Carvalho LVB, Pimentel JNS, Vieira JA, Castro VS, Borges RM, Nogueira SM, Tabalipa MM, Otero UB, Oliveira KMPG, Corrêa SM, Fonseca ASA, Alves SR, Moreira JC, Peres F e Menezes MAC contribuíram substancialmente no projeto, levantamento, análise e interpretação dos dados. Costa-Amaral IC, Teixeira LR, Mattos RCOC, Sarcinelli PN e Larentis AL participaram da elaboração do manuscrito e contribuíram na revisão crítica. Costa-Amaral IC, Alves SR, Mattos RCOC, Teixeira LR, Sarcinelli PN e Larentis AL participaram da aprovação final da versão a ser publicada. 


\section{Referências}

1. Osterreicher-Cunha P, Vargas Jr. EA, Guimarães JRD, Campos TM, Nunes CMF, Costa A, et al. Evaluation of bioventing on a gasoline-ethanol contaminated undisturbed residual soil. J Hazard Mater. 2004;110(1-3):63-76.

2. Tunsaringkarn T, Siriwong W, Rungsiyothin A, Nopparatbundit S. Occupational exposure of gasoline station workers to BTEX compounds in Bangkok, Thailand. Int J Occup Environ Med. 2012;3(3):117-25.

3. Okumura LL, Stradiotto NR. Simultaneous determination of neutral nitrogen compounds in gasoline and diesel by differential pulse voltammetry. Talanta. 2007;72(3):1106-13.

4. 4. Brasil. Ministério de Minas e Energia. Empresa de Pesquisa Energética. Balanço Energético Nacional 2014: relatório síntese - ano base 2013. Rio de Janeiro: EPE; 2014.

5. Brasil. Agência Nacional do Petróleo, Gás Natural e Biocombustíveis. Portaria $n^{\circ} 309$, de 27 de dezembro de 2001. Estabelece as especificações para a comercialização de gasolinas automotivas no Brasil. Diário Oficial da União. 28 dez 2001.

6. World Health Organization. Environmental Health Criteria; 214. Human exposure assessment. International Programme on Chemical Safety. Geneva: WHO; 2000.

7. International Agency for Research on Cancer. Some industrial chemicals and dyestuffs. Iarc Monogr Eval Carcinog Risk Chem Hum. 1982;29:1-398.

8. American Conference of Governmental Industrial Hygienist. Threshold limit values for chemicals substances and physical agents and biological exposure indices. Cincinnati, Ohio: ACGIH; 2003.

9. Tsitou P, Heneweer M, Boogaard PJ.

Toxicogenomics in vitro as an alternative tool for safety evaluation of petroleum substances and PAHs with regard to prenatal developmental toxicity. Toxicol In Vitro. 2015;29(2):299-307.

10. Brasil. Agência Nacional do Petróleo, Gás Natural e Biocombustíveis. Portaria $\mathrm{n}^{\mathrm{o}} 72$, de 26 de abril de 2000. Regulamenta os procedimentos a serem observados pelo distribuidor de combustíveis derivados de petróleo, álcool combustível, biodiesel, mistura de óleo diesel/ biodiesel especificada ANP e outros combustíveis automotivos para aquisição de gasolina automotiva, óleo diesel e óleo combustível para turbina elétrica, do produtor. Diário Oficial da União 27 abr 2000.

11. Brasil. Agência Nacional do Petróleo, Gás Natural e Biocombustíveis. Portaria $n^{\circ} 40$, de 25 de outubro de 2013. Regulamento técnico. Diário Oficial da União 25 out 2013.

12. Brasil. Ministério da Saúde. Portaria $n^{0} 776$, de 28 de abril de 2004. Dispõe sobre a regulamentação dos procedimentos relativos à vigilância da saúde dos trabalhadores expostos ao benzeno, e dá outras providências. Diário Oficial da União 29 abr 2004.

13. Brasil. Ministério da Saúde. Secretaria de Atenção à Saúde. Departamento de Ações de Planejamento Estratégicas. Risco químico: atenção à saúde dos trabalhadores expostos ao benzeno. Brasília: Ministério da Saúde; 2006. p. 48.

14. Meek MEB, Klaunig JE. Proposed mode of action of benzene-induced leukemia: Interpreting available data and identifying critical data gaps for risk assessment. Chem Biol Interact. 2010;184(1-2):279-85.

15. Hays SM, Pyatt DW, Kirman C, Aylward L. Biomonitoring Equivalents for benzene. Regul Toxicol Pharmacol. 2012;62(1):62-73.

16. Yoon BI, Li GX, Kitada K, Kawasaki Y, Igarashi K, Kodama Y, et al. Mechanism of action of benzene toxicity: cell cycle suppression in hemopoietic progenitor cells (CFU-GM). Exp Hematol. 2001;29(3):278-85.

17. Moro AM, Charão MF, Brucker N, Durgante J, Baierle M, Bubols G, et al. Genotoxicity and oxidative stress in gasoline station attendants. Mutat Res. 2013;754(1-2):63-70.

18. Azqueta A, Collins AR. The essential comet assay: a comprehensive guide to measuring DNA damage and repair. Arch Toxicol. 2013;87(6):949-68.

19. Collins AR. Measuring oxidative damage to DNA and its repair with the comet assay. Biochim Biophys Acta. 2014;1840(2):794-800.

20. Collins AR, Azqueta OA. Single-cell gel electrophoresis combined with lesion-specific enzymes to measure oxidative damage to DNA. Methods Cell Biol. 2012;112:69-92.

21. Moura-Correa MJ, Jacobina AJR, Santos SA, Pinheiro RDC, Menezes MAC, Tavares AM, et al. Exposição ao benzeno em postos de revenda de combustíveis no Brasil: Rede de Vigilância em Saúde do Trabalhador (Visat). Cienc Saúde Coletiva. 2014;19(12):4637-48.

22. Benites IC, Amado LL, Vianna RAP, Martino-Roth MG. Micronucleus test on gas station attendants. Genet Mol Res. 2006;5(1):45-54.

23. Rosa JCF, Fiegenbaum M, Soledar AL, Claus MS, Nunes ADS, Cardoso VV. Cytogenetic evaluation and the association with polymorphisms the CPY1A1 and NR1I3 genes in individuals exposed to BTEX. Environ Monit Assess. 2013;185(7):5883-90.

24. Trevisan P, Silva JN, Silva AP, Rosa RFM, Paskulin GA, Thiesen FV, et al. Evaluation of genotoxic effects of benzene and its derivates in workers of gas stations. Environ Monit Assess. 2014;186(4):2195-204.

25. Santiago F, Alves G, Otero UB, Tabalipa MM, Scherrer LR, Kosyakova N, et al. Monitoring of gas station attendants exposure to benzene, toluene, xylene (BTX) using three-color chromosome painting. Mol Cytogenet. 2014;7(1):15. 
26. Mitri S, Fonseca ASA, Otero UB, Tabalipa MM, Moreira JC, Sarcinelli PN. Metabolic polymorphisms and clinical findings related to benzene poisoning detected in exposed brazilian gas-station workers. Int J Environ Res Public Health. 2015;12(7):8434-47.

27. Lacerda LP, Dantas EBS, Cerqueira GS, Peron AP, Sousa JMC. Occupational toxicology study emphasizing the citotoxic and mutagenic activity among workers exposed to gasoline. Biotemas. 2015;28(3):135-41.

28. Corrêa SM, Arbilla G, Marques MRC, Oliveira KMPG. The impact of BTEX emissions from gas stations into the atmosphere. Atmos Pollut Res. 2012;3(2):163-9.

29. Arbilla G; Martins EM, Oliveira KMPG; Gatti LV. Exposure to volatile organic compounds in an ethanol and gasoline service station. Bull Environ Contam Toxicol. 2007;79(2):237-41.

30. Aebi H. Catalase in vitro. Methods Enzymol. 1984;105:121-6.

31. Habig WH, Jakoby WB. Assay for differentiation of glutathione $S$-transferases. Methods Enzymol. 1981;77:398-405.

32. Pinto JC, Schwaab M. Análise de dados experimentais. Rio de Janeiro: E-papers; 2007.

33. Brasil. Ministério do Trabalho e Emprego. Portaria no 14, de 20 de dezembro de 1995. NR $15-$ Atividades e operações insalubres. Anexo $n^{0} 13-A$ Benzeno. Diário Oficial da República Federativa do Brasil 14 dez 1995.

34. Brasil. Ministério do Trabalho e Emprego. Portaria $\mathrm{n}^{\circ} 3.214$, de 6 de junho de 1978. NR 15 - Atividades e operações insalubres. Brasília, DF, 1978. Diário Oficial da República Federativa do Brasil 6 jul 1978.

35. Carrieri M, Bonfiglioa E, Scapellatoa ML, Maccàa I, Tranfob G, Farandab P, et al. Comparison of exposure assessment methods in occupational exposure to benzene in gasoline filling-station attendants. Toxicol Lett. 2006;162(2-3):146-52.

36. Góth L. A simple method for determination of serum catalase activity and revision of reference range. Clin Chim Acta. 1991;196(2-3):143-51.

37. Amérand A, Vettier A, Moisan C, Belhomme M, Sébertet P. Sex-related differences in aerobic capacities and reactive oxygen species metabolism in the silver eel. Fish Physiol Biochem. 2010;36(3):741-7.
38. Tsuber V, Kadamov Y, Tarasenko L. Activation of antioxidant defenses in whole saliva by psychosocial stress is more manifested in young women than in young men. PLoS One. 2014;9(12):1-17.

39. Rappaport SM, Kim S, Lan Q, Vermeulen RCH, Waidyanatha S, Zhang L, et al. Evidence that humans metabolite benzene via two pathways. Environ Health Perspect. 2009;117(6):946-52.

40. Vlaanderen J, Portengen L, Rothman N, Lan Q, Kromhout H, Vermeulen R. Flexible metaregression to assess the shape of the benzeneleukemia exposure-response curve. Environ Health Perspect. 2010;118(4):526-32.

41. World Health Organization. International Programme on Chemical Safety. Environmental Health Criteria 150: benzene. Geneva: Who; 1993.

42. Arnold SM, Angerer J, Boogaard PJ, Hughes MF, O'Lone RB, Robison SH, et al. The use of biomonitoring data in exposure and human health risk assessment: benzene case study. Crit Rev Toxicol. 2013;43(2):119-53.

43. Boogaard PJ. Biomonitoring of the workplace and environment. General, applied and systems toxicology. 3rd ed. Hoboken: Wiley; 2009. p. 2559-89.

44. Guliaev AB, Hang B, Singer B. Structural insights by molecular dynamics simulations into specificity of the major human AP endonuclease toward the benzene-derived DNA adduct, pBQ-C. Nucleic Acids Res. 2004;32(9):2894-52.

45. Hayes JD, Flanagan JU, Jowsey IR. Glutathione transferases. Annu Rev Pharmacol Toxicol. 2005;45:51-88.

46. Huber PC, Almeida WP, Fátima A. Glutationa e enzimas relacionadas: papel biológico e importância em processos patológicos. Quim Nova. 2008;31(5):1170-9.

47. Boušová I, Skálová L. Inhibition and induction of glutathione $S$-transferases by flavonoids: possible pharmacological and toxicological consequences. Drug Metab Rev. 2012;44(4):267-86.

48. Brasil. Ministério do Trabalho e Emprego. Portaria $\mathrm{n}^{\circ} 3.214$, de 6 de junho de 1978. NR 16 Atividades e operações perigosas. Diário Oficial da União 6 jul 1978.

49. Arcuri ASA, Cardoso LMN. Acordo e legislação sobre o benzeno - 10 anos. São Paulo: Fundacentro; 2005. 